Volume 6, Issue 1 (2017) 69-78 | Published online 18 October 2017

The publication of the JEOD is supported by the Autonomous Province of Trento, Italy

\section{AUTHOR}

MAGNUS FREDRICSON

Skaraborgs Association of municipalities (Sweden)

magnus.fredricson@gmail.com

\section{JOHANNA MACTAGGART}

Lake Vänern Archipelago Biosphere Reserve (Sweden)

johanna.mactaggart@biosfarprogrammet.se

\title{
Social Economy in UNESCO Biosphere Reserves. A Multiperspective and Complexity Approach
}

\section{ABSTRACT}

The paper describes how social economy is a tool to further ambitions of sustainable development in model areas such as biosphere reserves. This is based on the notion of interdependencies between humans and nature in socio-ecological systems. Understanding the local resource base is vital to achieve a sustainable development, where a focus on mere economic development will blind policymakers and stakeholders to other resources and ambitions. By assessing a multitude of resources, outlined in the Community Capitals Framework, new paths towards sustainability will emerge. Resources include natural, cultural, social, human and others. The multi-perspective approach also enhances the need to understand and address complexity and how to manage complex processes. Strategies for this will include being as simple as possible but not simpler, being dynamic rather than static, and embracing uncertainty and unpredictability.

One application of the theoretical reasoning in the paper is the Biosphere Innovation System, where structures to promote and employ innovation for sustainable development are outlined, among them research linked to local knowledge, forums, financing and facilitated learning for policy makers and citizens.

\section{KEY-WORDS}

BIOSPHERE RESERVES; SOCIAL ECONOMY; COMPLEXITY; COMMUNITY CAPITALS; INNOVATION SYSTEM

\section{Acknowledgments}

The adaptation of the Community Capitals Framework and development of the dialogue assessment method was made possible by funding of the project Rural Regions 2020 from Interreg IVA KASK.

This article partly draws on a previous study, conducted by Magnus Fredricson and Magnus Ljung which was presented at the Nordic Association for Agricultural Science congress: "Nordic view to sustainable rural development", 16-18 June 2015, Riga, Latvia.

JEL Classification: L31; Q01; Q57 | DOI: http://dx.doi.org/10.5947/jeod.2017.005 


\section{Introduction}

This paper brings together social economy, entrepreneurial social infrastructure and UNESCO biosphere reserves by discussing some accessible theoretical frameworks. It aims to explore possibilities for enhancing social economy when viewing biosphere reserves as socio-ecological systems, as well as the role of biosphere reserves in providing rich growing grounds for enhancing social economy. The main research question is whether biosphere reserves contribute to an enhanced social economy, and in what way.

Around the world there are areas designated by UNESCO as model regions for sustainable development. They are called Biosphere Reserves (BRs). Currently there are 669 BRs in 120 countries within the UNESCO Man and the Biosphere (MAB) Programme. They are connected through a worldwide network where best practices are shared and showcased to other regions. BRs are areas that are designed to demonstrate and develop models for balanced relationships between humans and nature. These regions include areas of terrestrial and coastal ecosystems and represent different socioeconomic contexts, governance structures and ecosystem types. One of the intentions of the MAB Programme is that the designation of a BR can help raise awareness among local citizens and government authorities on issues related to sustainability, showing, i.e. how land use and conservation can go hand in hand. BRs add a unifying role and connect different actors through learning processes in a strategic way. They also serve as pilot areas where new approaches and new knowledge is tested to achieve a sustainable development.

The social economy is described by the EU as a "significant proportion of Europe's economy (...) intended to make profits for people other than investors or owners" (European Commission, n.d.). In our understanding, the social economy has the potential to contribute to a resilient society by providing sustentation for people affected by change processes or, i.e. with varying functionalities, thus, creating a socially, economically and ecologically sustainable society. We perceive social enterprises, started or run by social entrepreneurs, as important tools to enhance the social economy. The MAB Programme points out that "social entrepreneurs can contribute to BRs activities, hence contributing to sustainable development" (UNESCO, 2016: 9). A social enterprise is built around a mission statement that is not limited to achieve profits, but rather to (re-)invest in its members, employees or local community (ASC, 2013: 8). This is further outlined in the Social Enterprise \& Biosphere Reserve Development Framework (SEBR Framework), where it is implicitly stated that "Social capital shapes the quantity and quality of our social interactions and how well we can act collectively to tackle issues in our lives. It is therefore a critical resource for any intervention aiming to deliver lasting benefits" (ASC, 2013: 7).

This paper builds on efforts by, among others, the Executive Director of Assist Social Capital, Colin Campbell, and a network of biosphere reserves establishing a framework for social enterprise and biosphere reserves (ASC, 2013). The current action plan for the MAB Programme highlights the importance of BRs as incubators for social economy by providing "guidance and training to entrepreneurs and social enterprises on involvement in BRs" (UNESCO, 2016: 9). 
The article sets out to explore (i) what are the possibilities for an enhanced social economy by viewing BRs as socio-ecological systems, and (ii) how BRs contribute to a developed social economy through these possibilities. Moreover, this article proposes a model, the Biosphere Innovation System (BIS), outlining how a BR can contribute to enhancing social economy.

The paper initially introduces the concepts of biosphere reserves and social economy through a literature review (Section 2). Thereafter, the Community Capitals Framework approach (Section 3), along with the complexity and sustainable development concepts (Section 4) are presented. Section 5 outlines the locally developed Biosphere Innovation System (BIS), a proposed model for incubating social economy in a BR (Bergstrand, Björk and Molnar, 2011). While highlighting these frameworks independently, commonalities are further explored in the conclusions (Section 6). The article is built on desk research and reflection with regards to the parts concerning complexity and community capitals, as well as an empirical approach with regards to developing the BIS model and establishing the Lake Vänern Archipelago BR in Sweden.

\section{Literature review}

The concept of social-ecological systems emphasizes that people shall be seen as part of - not separate from-nature, and that the boundary between social and ecological systems is artificial and arbitrary (Folke et al., 2016). Resilience in society and its life-sustaining ecosystems is crucial for maintaining options for future human development. It should be noted that resilience is a term rooted in ecology, and that the transfer of an ecological notion into a sociological context poses challenges, even though it has become commonplace (Olsson et al., 2015). Loss of resilience can cause loss of valuable ecosystem services, and can lead to rapid negative changes in different situations for people, ecosystems or whole cultures. For example, if water is polluted by human activities, there will no longer be clean water available, and if pesticides and scaling of agricultural land lead to loss of wild bee populations, the service of pollination may be lost. Both these examples would have economic and social impacts on local communities and both examples are currently happening around the world today. Working for increased resilience means finding new ways to turn crises into innovative catalysts for sustainable development.

Building a society based solely on ambitions for economic growth, could blind policy makers and the society in general to the multitude of resources that could make up a base for working with sustainable development. In addition, diversity is key to building resilience in systems ${ }^{1}$. This also

Here diversity is interpreted in a broad sense "equating it with differentiation, heterogeneity, and variation" (Norberg and Cumming, 2008: 9). Resilience is the capacity of a system to "handle disturbance before a regime shift takes place." (ibid.: 3). Norberg and Cumming conclude that building a sustainable future "is about taking actions in the present to maintain and enhance the current and future resilience of desired trajectories of development of the social-ecological system" (ibid.: 279). 
apply to the way we view resources. Within the EU, there is a drive towards establishing a bio-based economy, where all physical resources are renewable, i.e. based on ecosystem services (European Commission, 2012). This is, indeed, one key ingredient to building a sustainable, fossil free, future and could well result in economic growth for areas that are struggling today. However, without a social entrepreneurship re-investment model, the associated economic growth might not contribute to social sustainability or local development.

\section{The Community Capitals Framework}

Professors Jan and Cornelia Flora of Iowa State University identify social capital, also referred to as "Entrepreneurial Social Infrastructure" (ESI), as a key factor contributing to a community's capacity to work together for the common good, i.e. a sustainable development (Flora and Flora, 1993). Strengthening social capital or, as later described "community capitals", will increase a community's capacity, thus creating opportunities for more effective interventions by public sector or others. Flora and Flora have further developed their thinking on social capital and established the Community Capitals Framework, a seven-perspective approach to resources within a community (Flora, n.d.). In their work, the authors apply a narrative and qualitative approach when assessing community capitals (ibid.). Interviews and conversations are paramount. Statistics and the local paper are other important sources when assessing capitals and understanding a local community.

In the Community Capitals Framework, capital is viewed as a set of collective resources, not just individual property. The types of capital are shown in a particular order, with natural capital (the natural environment), being the first and the basis for all the others, emphasizing the abovementioned notion of BRs as socio-ecological systems. In our work, we have expanded the understanding of natural capital as addressed by Flora and Flora, and refer to it as ecosystems based capital instead, to suit current strategies at both national and EU level. The seven types of capital are briefly introduced below:

- Ecosystems based capital includes air quality and the quality and quantity of water and soil, biodiversity, and the landscape. It can be viewed as a set of resources to be extracted or as a source of life that needs to be tended and cared for, depending on a group's cultural capital.

- Cultural capital determines how communities and groups within communities see the world, how they connect the seen and the unseen, what they take for granted and what they think is possible to change. Cultural capital is often highly determined by and determines natural capital.

- Human capital represents the skills, abilities, and knowledge that each human being possesses in a community.

- Social capital consists of interactions among people and groups for mutual support. It involves trust, shared norms, reciprocity, and working together. Social capital has two dimensions: bridging is the linking of local groups or institutions to resources and external partners with 
similar goals; bonding is the strengthening of internal organization and the capacity to take collective action based on the common backgrounds and experiences of the individuals or groups involved.

- Political capital refers to the codification of community's norms and values into standards that are supported by rules and regulations, which are enforced equally.

- Financial capital is the financial instruments, including but not limited to money that can be easily traded and monetized.

- Built capital refers to technology, infrastructure, tools, and machinery. While an individual can accumulate tools and machinery, collective goods such as roads, water systems, school buildings, and community centres, are generally best generated by a community working together.

\section{Complexity and sustainable development}

The connection and interplay between ecological wellness and social development is a vital part of understanding sustainability. This dates back to the Brundtland Commission ${ }^{2}$ and their definition of a sustainable development in 1987, based on the notion of "meeting essential human needs" (UN, 1987). A more recent definition is based on a "good life within planetary boundaries". According to Raworth (2017, no pagination), "Humanity's 21st century challenge is to ensure that every person has the resources they need to meet their human rights, while collectively we live within the ecological means of this one planet". The doughnut of planetary and social boundaries is a playfully serious approach to framing that challenge. This is a model based on the theory of Planetary Boundaries (Rockström et al., 2009).

Chris Mowles has pointed out that all human interaction is non-linear, meaning that human interaction will not play out in accordance with strict mechanistic sets of rules, but rather be complex (Mowles, 2012). The same could be said about many aspects of the life in the BR. In fact, pursuing a sustainable development will involve addressing complexity and managing conflicts of interests. (Kates Parris and Lieserowitz, 2005; Norberg and Cumming, 2008).

Holling (2001) presents a framework where socio-ecological and other complex systems move between two polarities denoted as poverty and rigidity traps, where lock-in prevents desired or needed development (Norberg and Cumming, 2008). The rigidity trap is based in lack of capacity for adaptation and dynamics. Björling (2016) has pointed out that the poverty trap is constituted by scarcity of resources, mandate, competencies and more. When a community is placed in a peripheral position where the multitude of capitals described above is neglected, it creates fragile situations. An example from an ecological system is the savannah where human over- and misuse flips it from a functioning ecosystem to a seemingly irreversible state of erosion, decreasing biodiversity and

2 Fromally known as the United Nations World Commission on Environment and Development (WCED). 
more (Holling, 2001). Obviously, the same type of collapse could occur in a community that is traumatized in different ways, i.e. by effects from concentrating and expanding urbanization or other transformational processes (Brenner, 2013).

Breaking out of a poverty or rigidity trap is one way of understanding challenges facing attempts to build a sustainable society, where establishing a social economy is an integral part. Interventions to achieve this would include, but not be limited to, adding resources and combining existing resources in a new way, commonly known as innovating. There is a case to be made that sustainable development requires transformation rather than incremental change (Holmberg et al., 2012). Innovation is a means to support the necessary transformation. Ways to strengthen capacities for this include better information processes, establishing networks and increasing diversity. Or, in other ways expanding abilities for playful (creative) experimentation, thus establishing social learning processes.

As it turns out, according to Holling (2001), strategies for addressing complex challenges would have to include the following aspects:

- Being as simple as possible but not simpler, enabling communication and understanding.

- Being dynamic rather than static, moving away from monitoring the past and rather evaluating the future and increase governance.

- Embracing uncertainty and unpredictability, the essence of complexity.

Connecting these realizations on complexity with the Community Capitals Framework indicates that investments in bridging and bonding social capital, as well as political capital, are means to strengthen information processes and networks. Striving for a dynamic inclusive approach and handling uncertainty and unpredictability would require investments, indeed changes, in the cultural capital. The cultural capital is often surveyed and understood as the answer to questions like: in this situation and set of circumstances, what is actually possible to develop or change? Furthermore, investments in human capital will increase the capacity to address complexity in a way that is "simple enough, but not too simple".

\section{The BR application: Biosphere Innovation System (BIS)}

Establishing the Lake Vänern Archipelago BR in Sweden, working towards a UNESCO designation, was a process of several years between 2005 and 2010. The process was actively involving local communities, individuals and wide range of stakeholders. During this time, several projects and activities were initiated. Some have been more successful and long-lasting than others. Harvesting lessons learned and analysing key components that act together to enhance social economics, was an important focus in the early days of the BR. In fact, it was under this perspective that the organization model of the future BR was agreed, i.e. a non-profit, non-governmental organization with a democratic governance. Indeed, the whole strategy and approach of the Lake Vänern Archipelago BR is based on the BIS-model hereby presented. 
The purpose of an innovation system is to promote development through providing support for innovations and entrepreneurs. An innovation system typically consists of a set of components such as actors, networks and institutions that are mutually interdependent. The actors could be divided into the three subgroups: production (i.e. enterprises, civil society organizations etc.), knowledge infrastructure (i.e. universities, research facilities, traditional place based knowledge, etc.), and supporting structures (i.e. public sector actors at local, national and international level). These actors are involved in a complex system of formal and informal networks, both within and between various interfaces. Innovation is not always born from formal, functional relationships, but rather from harmonious co-existence and co-creation of different actors. Establishing and maintaining an innovation system will hence include reinforcing trusting relationships between different actors, thus strengthening social capital, to create an effective ESI as described above. The conditions for the emergence of such relationship between the actors are determined largely by how the surrounding social institutions work and act. Social institutions in this context refer to the formal or informal rules (i.e. laws, policies, strategies, ideologies, etc.) that govern the behaviour of individuals and organizations. Based on research on processes within BRs, local participation seems to enhance and improve integration of multi-stakeholder approaches, thus have a positive effect on fostering sustainable development (Schultz, 2009). The BR organizations, as social institutions and drivers of social economy, inspire, motivate and mediate stakeholders towards a common goal, enabling stronger social contexts to evolve and make a foundation for social innovation.

BRs, as stated above, are model areas for sustainable development and should therefore be managed and measured as unique assets for long-term sustainable community development and the creation of resilient livelihoods. Entrepreneurs could serve as driving mechanisms for such a development in BRs if they interpret and exercise the core values of the BR in their business plans and practices. An innovation system within a BR would then include "extra" structures to enable and employ entrepreneurship of this sort, building on a multi perspective view on resources. It should be duly noted here, that supporting entrepreneurs is an obvious investment in human capital, which evokes (re-)investment of financial capital.

Biosphere entrepreneurship would derive from societal or other sustainability linked challenges. These enterprises exist to create social or other non-fiscal and environmental benefits while also creating financial returns. The Biosphere Innovation System (BIS) is designed to support the development of this kind of entrepreneurship (Bergstrand, Björk and Molnar, 2011). The driving force and vision behind BIS is an innovation system with scalable capabilities enabling global impact, in part achieved by transferring knowledge to other BRs through the UNESCO World Network of Biosphere Reserves (WNBR), since each BR has a mission from UNESCO to contribute with successful models of sustainable development, in terms of disseminating new knowledge, experiences and practical application.

A BIS therefore includes a set of values based in the BR as well as actors and activities that strengthen development of new businesses which focus on sustainable use and enhancement of the 
capacity of ecosystems to produce goods and services. The innovation system is strategically designed to enhance social capital. In practice, a BIS is composed of the following four parts (Bergstrand, Björk and Molnar, 2011):

- A research and development environment where theory, practice, and traditional knowledge are closely linked. This component is based on knowledge perspectives that build on specialization in different functions, diversity of activities and collaboration. It is a research and development environment designed to study and illustrate the basic structures needed for BIS to be successful. It describes the BR assets and resources related to the knowledge base, economic base, market size, social capital, quality of life, etc.

- A facilitated forum for BR entrepreneurs, strengthening networks, i.e. social capital. The forum may be virtual and/or physical, supporting the creation of new and strengthening existing businesses as well as providing networking opportunities. The forum provides opportunities for exploring innovative sustainable ways to utilize and enhance different local resources, including ecosystem services. It is characterized by the fact that it is inclusive, non-formal and open. The forum serves as a flexible venue for entrepreneurs where they can-in their own home environment-communicate with each other and with corresponding structures in other biosphere reserves. In addition, it provides an opportunity for citizens with innovative ideas to test them in a professional context through "open innovation". This kind of forum can also provide a physical location for targeted events such as public seminars, exhibitions, etc.

- A system providing financial support for existing and potential BR entrepreneurs. Financial capital is important for business development and regional growth. Successful entrepreneurship is not only closely linked to the availability of skilled labour and functional competitive markets, but also to access to capital markets and financial institutions. One of the main mandates of the BIS is to demonstrate that it is possible and profitable to invest in the utilization, re-investment in and enhancement of ecosystem services and other resources within the BR. Venture capitalists, banks, and funds could, i.e. be invited to invest in a "BIS fund" and in the entrepreneurial activities that are tied to the system. The results, in the form of practical experiences, may then be disseminated and implemented in other BRs.

- A learning platform for policy makers and citizens. As the world moves into more and more complexity, learning and local development will have to address the challenges posed by this evolutionary dynamic. The BIS just might prove to be simple and dynamic enough, enabling communication and dialogue as outlined above. Strengthening both human and social capital through learning processes is a vital part of the innovation system. Learning also affects the cultural capital of a community by altering the understanding of what is possible.

The BIS takes one step further in exploring models supporting a sustainable development in society. BRs have many inherent qualities, in which learning processes can be showcased. BR entrepreneurs, on the other hand, add value to the system by focusing on societal and environmental values in addition to economical directly in their business model. The innovation system itself should be seen as a supportive structure for social economics, in which important actors in society such 
as entrepreneurs, universities, financial institutions, municipalities, civic society and consumers are involved (Holmberg et al., 2012).

\section{Discussion and conclusions}

This article explores the possibilities for an enhanced social economy arising from viewing biosphere reserves (BRs) as socio-ecological systems, where people are part of, not separate from nature. Possibilities would include introducing a multi perspective view on resources to stakeholders and policymakers, enabling escapes from scarcity traps and other lock-ins. Where a multitude of resources are surveyed, valued and put into play a sustainable development is made possible. The designated role of BRs as model areas for sustainable development calls for foresight and a measure of progressive action based on these insights within the WNBR and reserves.

New possibilities to break lock-ins arise when resources are combined in new ways. The (re-)combination of resources is commonly referred to as innovation. Combining resources, that is innovating, for transformation or as previously described in this text "expanding abilities for playful experimentation thus establishing social learning processes" requires suitable arenas, where a BR could provide or even be one. A BR might also be a suitable scale for this kind of experimentation enabling a "simple enough but not to simple" approach as outlined above. The Biosphere Innovation System (BIS) is a model for achieving this.

In light of the above, we propose future research which aim at quantifying the impact on BRs in the social economy, as well as developing approaches to support BRs efforts in promoting social economy using the BIS model.

\section{References}

ASC (2013). Social Enterprise \& Biosphere Reserves Development Framework. Edinburgh Scotland, UK: Assist Social Capital CIC. Author: C. Campbell. Available at: http://social-capital.net/wp-content/uploads/2014/03/SEBRFinal.pdf [Accessed: May 2017].

Bergstrand, B.O., Björk, F. \& Molnar, S. (2011). Biosphere Entrepreneurship: A Pilot Study on social entrepreneurship in the biosphere reserve Lake Vänern Archipelago and Mount Kinnekulle, Sweden. Available at: http://media. vanerkulle.org/2013/09/297_BiosphereEntrepreneurship-A-Pilot-Study-Webversion.pdf [Accessed: May 2017].

Björling, N. (2016). Sköra stadslandskap: planeringsmetoder för att öppna urbaniseringens rumsliga inlåsningar. Chalmers Architecture.

Brenner, N. (2013). Theses on Urbanization, Public Culture, 25(1-69): 85-114. DOI: https://doi.org/10.1215/089923631890477

Fey, S. \& Flora, C. (2006). Using Community Capitals to Develop Assets for Positive Community Change, Retrieved from: http:// srdc.msstate.edu/fop/levelthree/trainarc/socialcapital/communitycapitalstodevelopassets-emeryfeyflora2006.pdf [Accessed: May 2017]

European Commission (2012). Innovating for Sustainable Growth: A Bioeconomy for Europe, COM(2012)60 final. 
European Commission (n.d.). Social economy in the EU. Directorate General for Internal Market, Industry, Entrepreneurship and SMEs (GROWTH). Available at: http://ec.europa.eu/growth/sectors/social-economy_en [Accessed: February 2017].

Flora, C.B. \& Flora, J.L. (1993). Entrepreneurial Social Infrastructure: A Necessary Ingredient, The Annals of the Academy of Social and Political Sciences, (529)1: 48-58. DOI: https://doi.org/10.1177/0002716293529001005.

Flora, C.B. (1995). Social Capital and Sustainability: agriculture and communities in the Great Plains and Corn Belt, Research in Rural Sociology and Development: A Research Annual (6): 227-246, Iowa State University.

Folke C., Biggs R., Norström A.V., Reyers B. \& Rockström, J. (2016). Social-ecological resilience and biosphere-based sustainability science, Ecology and Society, 21(3):41.

Holling, C.S. (2001). Understanding the Complexity of Economic, Ecological, and Social Systems, Ecosystems, (4)5: 390-405.

Holmberg, J., Lundqvist, U., Svanström, M. \& Arehag, M. (2012). The University and Transformation towards Sustainability. The strategy used at Chalmers University of Technology, International Journal of Sustainability in Higher Education, (13)3: 219-231.

Kates, R.W., Parris, T.M. \& Leiserowitz, A.A. (2005). What Is Sustainable Development? Goals, Indicators, Values, and Practice, Environment: Science and Policy for Sustainable Development, (47)3: 8-21.

Ljung, M. \& Fredricson, M. (2015). Assessing Interventions Supporting Sustainable Development in Rural Areas - a Dialogical Approach, NJF 25th congress proceedings; Nordic view to sustainable rural development, 16-18 June 2015 Riga, Latvia, pp. 440-444.

Mowles, C. (2012). Rethinking Management - Radical Insights from the Complexity Sciences. Routledge.

Norberg, J. \& Cumming, G. (2008). Complexity Theory for a Sustainable Future. In: M. Anderies \& J. Norberg, (Eds.), Theoretical Challenges: Information Processing and Navigation in Social-Ecological Systems. New York: Columbia University press.

Olsson, L., Jerneck, A., Thoren, H., Persson, J. \& O'Byrne, D. (2015) Why resilience is unappealing to social science: Theoretical and empirical investigations of the scientific use of resilience, Science Advances, (1)4: no pagination.

Raworth, K. (2017). Exploring Doughnut Economics. Available at: https://www.kateraworth.com/doughnut/ [Accessed: February 2017].

Rockström, J., Steffen, W., Noone, K., Persson, Å., Chapin, F.C., Lambin, E. F., Lenton, T.M., Scheffer, M., Folke, C.H., Schellnhuber, J., Nykvist, B., de Wit, C.A., Hughes, T., van der Leeuw, S., Rodhe, H. Sörlin, S., Snyder, P. K., Costanza1, R., Svedin, U., Falkenmark, M., Karlberg, L., Corell, R.W., Fabry, V.J., Hansen, J., Walker, B., Liverman, D., Richardson, K., Crutzen, P. \& Foley, A.J. (2009). A safe operating space for humanity. Nature, (461): 472-475.

Schultz, L. (2009). Nurturing resilience in social-ecological systems. Lessons learned from bridging organizations. PhD thesis (supervisor Prof. Folke, C.), Department of Systems Ecology, Stockholm University.

UN (1987). Report of the World Commission on Environment and Development: Our Common Future. Available at: http://www.un-documents.net/our-common-future.pdf [Accessed: May 2017].

UNESCO (2016). Lima Action Plan for UNESCO Man and the Biosphere (MAB) Programme and its World Network of Biosphere Reserves (2016-2025). Available at: http://www.unesco.org/fileadmin/MULTIMEDIA/HQ/SC/ pdf/Lima_Action_Plan_en_final.pdf [Accessed: February 2017]. 